Parsonage, M. (1969). Prescriber's fournal, 1, 8.

Pashayan, H., Pruzansky, D., and Prunzansky, S. (1971). Lancet, 2, 702. Registrar General for England and Wales (1966). Classification of Occupations. London, H.M.S.O.

Roman, I. C., and Caratzali, A. (1971). British Medical fournal, 4, 234.

Rosalki, S. B., Tarlow, D., and Rau, D. (1971). Lancet, 2, 376.

Sorrell, T. C., Forbes, I. J., Burness, F. R., and Rischbieth, R. H. C. (1971). Lancet, 2, 1233.
South, J. (1972). Lancet, 2, 1154

Speidel, B. D., and Meadow, S. R. (1972). Lancet, 2, 839.

Tattersall, R. (1965). Practitioner, 194, 68.

Thompson, R. P. H., and Williams, R. (1970). Lancet, 2, 466.

de Toni, E., Massimo, L., Vianello, M. G., and Bicarelli, F. D. (1966) Annales de Génétique, 9 , 99

Trolle, D. (1968). Lancet, 1, 251

Wilson, J. T. (1969). Lancet, 2, 214

\title{
Pattern of Gastric Emptying after Vagotomy and Pyloroplasty
}

\author{
M. R. COLMER, G. M. OWEN, R. SHIELDS
}

British Medical fournal, 1973, 2, 448-450

\section{Summary}

The pattern and rate of gastric emptying have been studied in 16 patients before and after vagotomy and pyloroplasty. The rate of emptying, expressed as half life in minutes, was not greatly changed by operation. After operation, however, there was a rapid initial phase of emptying, particularly marked in patients who had postvagotomy diarrhoea.

\section{Introduction}

The operation of vagotomy and pyloroplasty is widely used in the treatment of duodenal ulcer but its long-term effects on gastric motility and emptying are not clear. The results of the few studies which have been undertaken have been conflicting. Buckler (1967) observed that the total emptying time of the stomach was prolonged after operation. Madsen and Pederson (1968), George et al. (1968), and McKelvey (1970) noted that after operation the stomach emptied more rapidly, particularly in patients with postoperative diarrhoea. The methods used in these studies, however, had some defects; in none was the emptying of ordinary food measured, and in three nasogastric intubation was necessary. In only one study (George et al., 1968) were the same patients studied both before and after operation. Cowley et al. (1972) observed little difference in gastric emptying of solid food between patients after truncal vagotomy and pyloroplasty and a group of control patients except in the early postoperative period.

This paper is a preliminary report of a study of gastric emptying in patients before and after vagotomy and pyloroplasty.

\section{Patients}

Sixteen patients were studied before and after vagotomy and pyloroplasty. Details of the gastroduodenal disease and the type of operation performed are given in table I. In all cases the main

Cardifi Royal Infirmary, Cardiff

M. R. COLMER, F.R.c.s., Research Assistant (Now at the University of Liverpool)

R. SHIELDS, M.D., F.R.C.s., Reader in Surgery (Now at the University

Velindre Hospital (South Wales and Monmouthshire Radiotherapy Service), Cardiff

G. M. OWEN, M.sc., Principal Physicist TABLE I-Details of Gastroduodenal Disease and Operations performed in 16
Patients

\begin{tabular}{ll|c|c|c|c|c}
\hline & $\begin{array}{c}\text { No. of } \\
\text { Patients }\end{array}$ & $\begin{array}{c}\text { T.V. and } \\
\text { F.P. }\end{array}$ & $\begin{array}{c}\text { S.V. and } \\
\text { F.P. }\end{array}$ & $\begin{array}{c}\text { T.V. and } \\
\text { H.M.P. }\end{array}$ & $\begin{array}{c}\text { S.V. and } \\
\text { H.M.P. }\end{array}$ \\
\hline $\begin{array}{llll}\text { Gastric ulcer .. } \\
\text { Duodenal ulcer }\end{array}$ & $\ldots$ & 5 & 4 & 2 & 1 & 1 \\
$\begin{array}{l}\text { Gastric and duodena } \\
\text { ulcer }\end{array}$ & 8 & 4 & 2 & 1 & 1 \\
Hiatus hernia .. & $\ldots$ & 2 & 1 & 1 & 1 & \\
\hline
\end{tabular}

T.V. = Truncal vagotomy. S.V. = Selective vagotomy. F.P. = Finney pyloroplasty.

H.M.P. = Heineke-Mikulicz pyloroplasty.
Note: (1) In selective vagotomy all the gastric branches of the anterior and posterior (2) vagi were cut, leaving the hepatic and coeliac branches intact The pyloroplasty was made using an incision of about 3 in. $(7.5 \mathrm{~cm})$ and closed with two layers of sutures.

indication for operation was intractable pain. The mean age ( \pm 1 S.D.) was $51 \pm 13$ years.

Preoperative studies of gastric emptying were performed from two days to one year before operation. At least nine weeks were allowed to elapse after operation before gastric emptying was again measured to avoid the period of transient postoperative gastric stasis (Cowley et al., 1972; Davies et al., 1973). Usually patients were studied during the first year after vagotomy and pyloroplasty; four were studied less than three months and five were studied more than one year after operation.

Seven of the 16 patients experienced postoperative diarrhoea (defined as the passage of liquid stools three or more times daily) -four had continuous diarrhoea, two had episodic attacks lasting one day and occurring at intervals of one to three weeks, and one had diarrhoea only during the first postoperative month.

\section{Method}

Details of the method have been described previously (Griffith et al., 1966; Griffith et al., 1968). The upper abdomen was scanned, by an automatic scintiscanner with two detectors, at timed intervals after ingestion of a standard breakfast labelled with radioactive chromium $\left({ }^{51} \mathrm{Cr}\right)$. From each scan the amount of meal remaining in the stomach was calculated and expressed in terms of scanner counts. The first scan was performed as soon as possible after the end of the meal, usually at about 10 minutes, but in no case was there a delay of more than 16 minutes. For practical reasons it was not possible to standardize this interval.

For each patient the radioactivity remaining in the stomach at each scan $\left(\mathrm{C}_{1}, \mathrm{C}_{2}, \mathrm{C}_{3}\right.$, etc.) was calculated and plotted against time on a semilogarithmic scale (see fig.). The slope of the line through the points was straight in all but one of the patients. Thus, from the time of the first scan (10 minutes after the end of the meal) until the emptying process was almost complete, food left the stomach in an exponential manner. The rate of emptying could therefore be expressed as the half life $\left(t \frac{1}{2}\right)$ of the 


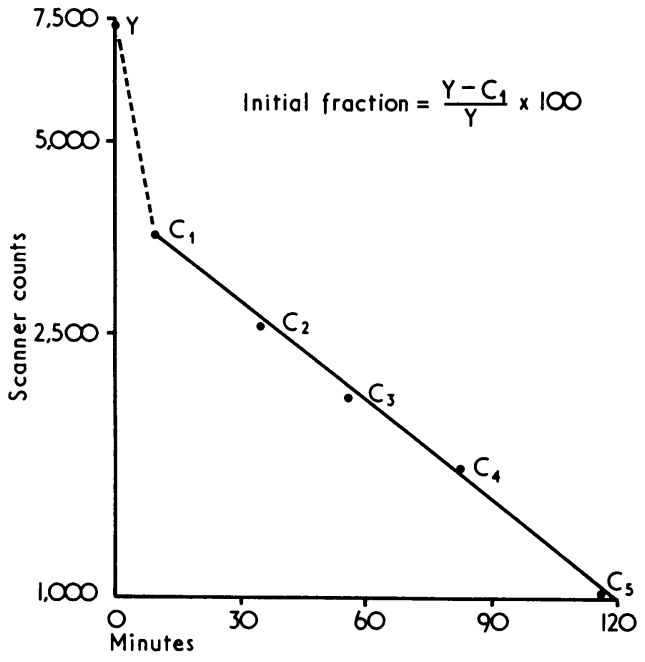

Example of emptying curve illustrating calculation of initial fraction.

meal in the stomach. After operation, however, the initial phase of emptying before the first scan was very rapid in most of the patients. To obtain a measure of this fast initial component of gastric emptying (represented by the dotted line in the fig.) the amount of the meal which had left the stomach by the time of the first scan was calculated and expressed as a percentage of the meal eaten. This value, called the initial fraction, was obtained

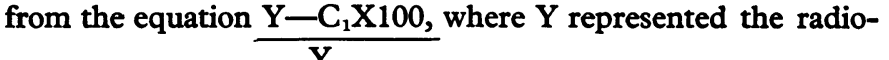

activity in the meal eaten and $C_{1}$ represented the radioactivity in the meal remaining in the stomach at the time of the first scan, both $Y$ and $C_{1}$ being expressed as scanner counts.

$A$ value for $Y$ was obtained in the following way. The dose of ${ }^{51} \mathrm{Cr}$ was counted in a ring of Geiger counters; from this count was subtracted the number of counts due to the ${ }^{51} \mathrm{Cr}$ in food residue on the plates and cutlery after the meal. Thus a value was obtained for the amount of ${ }^{51} \mathrm{Cr}$ (in Geiger counts) eaten by the patient. To convert Geiger counts to scanner counts a conversion factor, obtained by scanning several known amounts of ${ }^{51} \mathrm{Cr}$ in a dummy stomach immersed in a water phantom, was used.

\section{Results}

In 15 of the 16 patients the postoperative emptying process subsequent to the first scan was exponential and the rate of gastric emptying, as measured by the $t \frac{1}{2}$, was slightly but not significantly faster after operation (table II). In one patient, however, postoperative emptying did not follow an exponential course and therefore no calculation of the $t \frac{1}{2}$ could be made.

After operation an average of nearly $40 \%$ of the meal left the stomach by the time of the first scan-that is, by about 10 minutes after the end of the meal. This postoperative initial fraction was significantly greater $(P<0.001)$ than the mean initial fraction (12.5\%) before operation (table II).

TABLE II-Half Life of Meal in Stomach and Initial Fraction of Meal leaving Stomach before and after Vagotomy and Pyloroplasty

\begin{tabular}{|c|c|c|c|c|}
\hline & & & $\begin{array}{l}t_{2}^{1} \text { in Minutes } \\
\text { (Mean } \pm \text { S.D. } \\
15 \text { Patients* }\end{array}$ & $\begin{array}{c}\text { Initial Fraction } \% \\
\text { (Mean } \pm \text { S.D.) } \\
16 \text { Patients }\end{array}$ \\
\hline $\begin{array}{l}\text { Before operation } \\
\text { After operation }\end{array}$ & $\begin{array}{l}\ldots \\
\cdots\end{array}$ & $\therefore$ & $\begin{array}{l}63 \cdot 5 \pm 14 \cdot 8 \\
55 \cdot 7 \pm 23 \cdot 7\end{array}$ & $\begin{array}{l}12 \cdot 5 \pm 13 \cdot 6 \\
39 \cdot 3 \pm 16 \cdot 1\end{array}$ \\
\hline Mean difference \pm S.E. & $\cdots$ & .. & $7 \cdot 8 \pm 6 \cdot 4$ & $26 \cdot 8 \pm 5 \cdot 4$ \\
\hline Significance of difference $†$ & 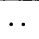 & $\ldots$ & $P>0.2$ & $P<0.001$ \\
\hline
\end{tabular}

* One not exponential after operation. †Student's $t$ test for paired data.
The mean interval ( \pm 1 S.D.) between the end of the meal and the first scan was $11 \cdot 7 \pm 2 \cdot 3$ minutes before operation and $10 \cdot 4 \pm 3.0$ minutes after operation. In only three patients was this interval greater after operation. Thus the observed increase in the initial fraction was not caused by an increase in the interval between the end of the meal and the first scan.

The patients were then divided into two groups depending on the presence or absence of diarrhoea (defined above) after operation (table III). Before operation the mean $t \frac{1}{2}$ of the meal in the stomach did not differ between the two groups. In those who had postoperative diarrhoea the mean $t \frac{1}{2}$ of the meal in the stomach was less after operation than before, but the difference did not reach statistical significance $(P>0.05)$. The mean postoperative rate of emptying (as measured by the $t \frac{1}{2}$ ) was faster in those with diarrhoea than in those without but the difference was not significant $(P>0 \cdot 1)$. In both groups, however, the increase in the initial fraction after operation was significant, the mean being $30.7 \%$ in those with diarrhoea $(P<0.05)$ and $23.6 \%$ in those without diarrhoea $(P<0.01)$. The mean postoperative initial fraction in those with diarrhoea $(47 \cdot 4 \%)$ was significantly greater $(P<0.02)$ than that in those without diarrhoea $(26.3 \%)$. The mean preoperative initial fraction did not differ between the two groups. In six of the seven patients with diarrhoea the initial fraction after operation was outside the $95 \%$ confidence limits of the preoperative values for all the patients.

TABLE III-Half Life of Meal in Stomach and Initial Fraction of Meal leaving Stomach in Patients with and without Postoperative Diarrhoea

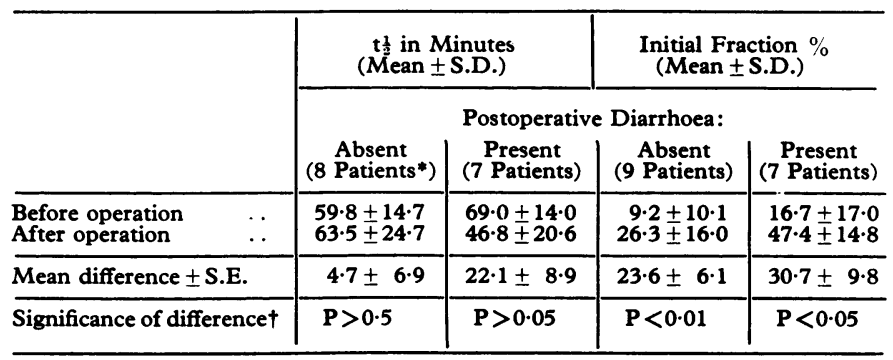

*One not exponential after operation. +Student's $t$ test for paired data.

\section{Discussion}

From these results we conclude that the operation of vagotomy and pyloroplasty alters the pattern of gastric emptying more than its rate. Before operation a patient emptied his stomach in a simple exponential fashion. After operation the greater part of the emptying process was again observed to be exponential but it was noted that during the interval between the end of the meal and the first scan an unexpectedly large part of the meal had left the stomach. Thus after operation there appeared to be two components in the emptying slope. There was an initial fast component (within the first 10 minutes after the end of the meal), when a rapid "dump" of a large part of the meal from the stomach occurred. Thereafter emptying was exponential and had a rate constant similar to that observed in the same patient before operation. In those patients who experienced diarrhoea after operation there was a particularly marked change in the pattern and speed of gastric emptying, with a very much larger proportion of the meal leaving the stomach initially compared with those without diarrhoea. These conclusions are drawn from the pooled results, both for different types of operation and for different types of primary disease (table I).

The explanation for the observed changes in the pattern of gastric emptying is not clear. In the presence of a large patulous pyloroplasty gravity may play a greater part than usual in emptying. The duodenal brake may be less effective, either because the duodenal resistance is reduced or because the duodenal reflexes are less effective (Thomas, 1957). Increase in gastric tone has been observed after vagotomy (Rowe et al., 1952; Nelsen et al., 1967), which may lead to reduced gastric 
capacity. The receptive relaxation of the stomach may be abolished by vagotomy (Olbe and Jackson, 1963; Weisbrodt et al., 1969).

Rapid gastric emptying may lead to acute distension of the jejunum or rapid intestinal transit of food, both of which may lead to postprandial diarrhoea. On these grounds, however, it is difficult to explain episodic diarrhoea.

Whatever may be the cause of the altered pattern of emptying after operation, it is conceivable that an attempt to retain more normal gastric emptying by modification of operative technique in some or all patients might reduce the incidence of troublesome sequelae. Recent reports show that this has been achieved by the use of highly selective vagotomy without a drainage procedure (Humphrey et al., 1972; Johnston et al., 1972).

We are grateful to Professors A. P. M. Forrest and P. B. Kunkler in whose departments this investigation was carried out. We are indebted to Tenovus for the donation of the automatic scintiscanner. This work was supported by a grant from the Medical Research Council.

A preliminary communication of this paper was read to the Surgical Research Society (Colmer et al., 1969).

\section{References}

Buckler, K. G. (1967). Gut, 8, 137

Colmer, M. R., Owen, G. M., Davies, W. T., and Shields, R. (1969). British fournal of Surgery, 56, 702.

Cowley, D. J., Vernon, P., Jones, T., Glass, H. I., and Cox, A. G. (1972). Gut, 13, 176

Davies, W. T., Griffith, G. H., Owen, G. M., and Shields, R. (1973). To be published.

George, J. D., Connell, A. M., and Kennedy, T. (1968). Gut, 9, 732.

Griffith, G. H., Owen, G. M., Kirkman, S., and Shields, R. (1966). Lancet, $1,1244$.

Griffith, G. H., Owen, G. M., Campbell, H., and Shields, R. (1968). Gastroenterology, 54, 1.

Humphrey, C. S., Johnston, D., Walker, B. E., Pulvertaft, C. N., and Goligher, J. C. (1972). British Medical fournal, 3, 785.

Johnston, D., Humphrey, C. S., Walker, B. E., Pulvertaft, C. N., and Goligher, J. C. (1972). British Medical fournal, 3, 788.

McKelvey, S. T. D. (1970). British fournal of Surgery, 57, 741.

Madsen, P., and Pederson, G. (1968). Scandinavian fournal of Gastroenterology, 3,545 .

Nelsen, T. S., Eigenbrodt, E. H., Keoshian, L. A., Bunker, C., and Johnson, L. (1967). Archives of Surgery, 94, 821 .

Olbe, L., and Jackson, B. (1963). Gastroenterology, 44, 787.

Rowe, C. R., et al. (1952). Surgery, 32, 226.

Thomas, J. E. (1957). Physiological Reviews, 37, 453.

Weisbrodt, N. W., Wiley, J. N., Overholt, B. F., and Bass, P. (1969). Gut, 10,543 .

\title{
Cyclophosphamide in Treatment of Systemic Lupus Erythematosus: 7 Years' Experience
}

\author{
P. H. FENG, F. J. JAYARATNAM, E. P. C. TOCK, C. S. SEAH
}

British Medical fournal, 1973, 2, 450-452

\section{Summary}

This paper describes our experience with cyclophosphamide in the treatment of systemic lupus erythematosus. Since 1965 42 such patients have been treated either singly with cyclophosphamide or in combination with steroid. Serious complications have been rare except for amenorrhoea, which occurred in 14 out of 32 patients within the reproductive period. Our experience suggests that cyclophosphamide has an important, though not primary, part to play in the therapy of this disease.

\section{Introduction}

Hill and Scott (1964) first described the successful use of cyclophosphamide in the treatment of a patient with systemic lupus erythematosus (S.L.E.) who had failed to respond to steroids. Their results were confirmed by Seah et al. (1966) and Hadidi (1970). Similarly, Cameron et al. (1970) successfully treated three cases of lupus nephritis with cyclophosphamide. In experimental studies, Russell and Hicks (1968) showed that cyclophosphamide in appropriate doses decreased the incidence of severe spontaneous autoimmune renal disease from $100 \%$ to $6.7 \%$ in female (NZB and NZW)

\footnotetext{
Medical Unit, Thomson Road General Hospital, Toa Payoh Rise,
Singapore 11

P. H. FENG, M.R.C.P.GlasG., Consultant Physician
}

Medical Unit III, Outram Road General Hospital, Singapore 3

F. J. JAYARATNAM, F.R.A.C.P., Consultant Physician

C. S. SEAH, F.R.C.P., F.R.A.C.P., Head and Senior Physician

Department of Pathology, University of Singapore

E. P. C. TOCK, M.D., M.C.P.A., Associate Professor of Pathology
F1 hybrid mice. It appears, therefore, that cyclophosphamide could be a useful drug in the long-term management of S.L.E. We report here our experience with cyclophosphamide in the management of S.L.E. over a seven-year period. The patients originally reported on by Seah et al. (1966) are included.

\section{Patients and Methods}

Forty-two patients were studied. All fulfilled the criteria for S.L.E. as proposed by Dubois (1966). Thirty-seven patients were female and five were male, again showing the preponderance of females over males. Age at onset varied from 15 to 62 years, but was mostly ( $71 \%$ of cases) between 15 and 30 years. A positive L.E. phenomenon was found in $83 \%$, hypergammaglobulinaemia in $80 \%$, and a raised E.S.R. (more than $40 \mathrm{~mm}$ in one hour) in $85 \%$ of the patients. Fiftyfive per cent, were anaemic (haemoglobin less than $10 \mathrm{~g} / 100$ $\mathrm{ml}$ ), $30 \%$ had thrombocytopenia (platelets less than 100,000/ $\mathrm{mm}^{3}$ ), and $25 \%$ had leucopenia (W.B.C. less than 4,000 / $\mathrm{mm}^{3}$ ). Abnormalities in the urine were found in $77 \%$ of the patients, and six presented with the features of classical nephrotic syndrome. Altogether 40 renal biopsies were carried out in 31 patients.

All the patients were admitted to the medical unit at Thomson Road General Hospital. Biochemical tests were carried out as described previously (Seah et al., 1966). Patients with severe constitutional symptoms were given prednisolone 60-30 mg daily, and those with minor systemic disturbances were started on prednisolone $15 \mathrm{mg}$ a day. As soon as improvement occurred the dose of prednisolone was gradually decreased and cyclophosphamide was instituted. Initially this was given intravenously as a single weekly dose of $400 \mathrm{mg}$, but after discharge oral tablets were substituted, the dosage being $100 \mathrm{mg}$ four times a week. All patients reported regularly to the follow-up clinic and cyclophosphamide was continued unless the total white cell count fell below $3,000 / \mathrm{mm}^{3}$ 